\title{
Treatment outcomes after initiation of exenatide twice daily or insulin in clinical practice: I 2-month results from $\mathrm{CHOICE}$ in six European countries
}

This article was published in the following Dove Press journal:

Diabetes, Metabolic Syndrome and Obesity:Targets and Therapy

25 April 2013

Number of times this article has been viewed

\section{Claes-Göran Östenson' \\ Stephan Matthaei² \\ Matthew Reaney ${ }^{3}$ \\ Thure Krarup ${ }^{4}$ \\ Bruno Guerci ${ }^{5}$ \\ Jacek Kiljanski6 \\ Carole Salaun-Martin ${ }^{7}$ \\ Hélène Sapin ${ }^{7}$ \\ David Bruhn ${ }^{8}$ \\ Chantal Mathieu ${ }^{9}$ \\ Michael Theodorakis ${ }^{10}$ \\ 'Department of Molecular Medicine and Surgery, Karolinska Institute, \\ Stockholm, Sweden; ${ }^{2}$ Diabetes-Center \\ Quakenbrück, Quakenbrück, Germany; \\ ${ }^{3}$ Eli Lilly, Windlesham, Surrey, UK; \\ ${ }^{4}$ Department of Endocrinology I, \\ Bispebjerg Hospital, Copenhagen, \\ Denmark; ${ }^{5}$ Diabetology, Metabolic \\ Diseases and Nutrition, Brabois \\ Hospital, CHU Nancy, and INSERM \\ CIC, ILCV, Vandoeuvre Lès Nancy, \\ France; ${ }^{6}$ Eli Lilly, Warsaw, Poland; \\ ${ }^{7}$ Eli Lilly, Neuilly Cedex, France; \\ ${ }^{8}$ Eli Lilly, San Diego, California, \\ USA; ' Department of Endocrinology, \\ UZ Gasthuisberg, Leuven, Belgium; \\ ${ }^{10}$ Department of Clinical Therapeutics, \\ University of Athens School \\ of Medicine, Athens, Greece*}

*Michael Theodorakis was affiliated with the institution shown at the time of the study, but has since left this institution

Correspondence: Claes-Göran Östenson Department of Molecular Medicine and Surgery, Karolinska Institute, Karolinska University Hospital Solna, D2:04, SE-17I 76 Stockholm, Sweden Tel +46 851776200

Fax +46851773096

Email claes-goran.ostenson@ki.se
Objective: The CHanges to treatment and Outcomes in patients with type 2 diabetes initiating InjeCtablE therapy (CHOICE) study assessed time to, and reasons for, significant treatment change after patients with type 2 diabetes (T2DM) initiated their first injectable glucoselowering therapy (exenatide twice daily [BID] or insulin) in routine clinical practice, and these patients' clinical outcomes, in six European countries. This paper reports interim data from the first 12 months of the study.

Research design and methods: CHOICE (NCT00635492) is a prospective, noninterventional, observational study. Clinical data were collected at initiation of first injectable therapy and after approximately 3, 6, and 12 months.

Results: Of 2497 patients enrolled in CHOICE, 1096 in the exenatide BID and 1239 in the insulin cohorts had $\geq 1$ post-baseline assessment and were included in this analysis. Overall, $32.2 \%$ of the exenatide BID cohort and $29.1 \%$ of the insulin cohort (Kaplan-Meier estimates) had significant treatment change during the first 12 months, most commonly discontinuing injectable therapy or adding new T2DM therapy, respectively. Glycemic control improved in both cohorts, but weight loss occurred only in the exenatide BID cohort (mean change $-3.3 \mathrm{~kg}$ ). Hypoglycemia occurred in $13.2 \%$ of the exenatide BID cohort and $28.6 \%$ of the insulin cohort ( $82.8 \%$ and $55.6 \%$ of these patients, respectively, received sulfonylureas). The post hoc endpoint of glycated hemoglobin $<7 \%$, no weight gain, and no hypoglycemia was attained at 12 months by $24.3 \%$ and $10.3 \%$ of patients who had data at 12 months and who were receiving exenatide BID and insulin, respectively.

Conclusion: About $30 \%$ of patients in CHOICE changed treatment in the first 12 months after initiation of first injectable therapy (exenatide BID or insulin). Overall, both cohorts achieved improved glycemic control, which was accompanied by a mean weight loss in the exenatide BID cohort.

Keywords: type 2 diabetes mellitus, exenatide, insulin, injectable therapy

\section{Introduction}

Progressive beta-cell dysfunction prevents many patients with type 2 diabetes mellitus (T2DM) from maintaining adequate glycemic control with oral antidiabetic drugs (OADs). ${ }^{1,2}$ Patients whose glycemic control deteriorates despite OAD treatment require initiation of injectable glucose-lowering therapies: insulin or a glucagon-like peptide-1 (GLP-1) receptor agonist.

Increasingly, successful treatment of T2DM is seen as requiring individualization for each affected patient, with specific patient preferences, characteristics, susceptibilities to adverse events, potential for weight gain, and hypoglycemia playing a major role in drug selection. ${ }^{1}$ Weight gain resulting from some antidiabetic medications may 
be associated with worsening markers of insulin resistance and cardiovascular risk. ${ }^{1}$ In instances where weight loss is considered important, initial injectable treatment with a GLP-1 receptor agonist can be considered as an alternative to insulin therapy because GLP-1 receptor agonists generally have the potential advantage of weight loss. ${ }^{1}$ Further, GLP-1 receptor agonists have been associated with a low risk of hypoglycemia (unless used with a sulfonylurea) and have been shown to have glucose-lowering efficacy similar to that of insulin glargine or biphasic insulin aspart. ${ }^{1,3-8}$ As such, the National Institute for Health and Clinical Excellence (NICE) in the UK suggests that the patients with T2DM likely to benefit most from GLP-1 receptor agonists are those for whom excess weight is an issue. ${ }^{9}$ Epidemiological data from the USA ${ }^{10,11}$ and $\mathrm{UK}^{12}$ suggest that the mean body mass index (BMI) of people prescribed GLP-1 receptor agonists is $38-40 \mathrm{~kg} / \mathrm{m}^{2}$ - somewhat higher than estimates for the general T2DM populations in both these countries. ${ }^{13,14}$ Conversely, non-obese patients are more likely than obese patients to be prescribed insulin therapy in the UK, as are patients aged $\leq 60$ years, those with more severe T2DM (diabetes complications and higher glycated hemoglobin $\left.\left[\mathrm{HbA}_{1 \mathrm{c}}\right]\right)$, and patients who have received OAD therapy, compared with those aged $>60$ years, without severe illness, and who have previously received lifestyle interventions only $(P \leq 0.01$ for all $){ }^{15}$

Preclinical data have suggested that GLP-1 and GLP-1 receptor agonists may protect beta cells, and improve beta-cell mass and function. ${ }^{16-20}$ These actions could potentially slow the progression of T2DM, although their clinical relevance has not been established. Results of a recent meta-analysis support the use of GLP-1 receptor agonists as the second-line therapy of choice after initial metformin therapy. ${ }^{21}$

Exenatide twice daily (BID) was the first GLP-1 receptor agonist to be approved in Europe (in 2006). ${ }^{22,23}$ Despite accumulated clinical experience, it has not been clear how, and in whom, exenatide BID is initiated in routine clinical practice across Europe, and limited information is available regarding its effectiveness in real-life settings across Europe. Moreover, it is unclear why, whether, and how exenatide BID therapy is later modified. Well-designed, scientifically rigorous prospective observational studies of clinical practice are necessary to fill these information gaps. ${ }^{24,25}$ The data gathered by such studies could then be used to enhance the evidence on which the management of T2DM is based.

The American Diabetes Association and European Association for the Study of Diabetes have called for clinical practice data for newer therapies to establish safety and effectiveness alongside best current treatment, and to provide "meaningful data on meaningful outcomes." CHOICE (CHanges to treatment and Outcomes in patients with type 2 diabetes initiating InjeCtablE therapy) is the first prospective observational study to evaluate patterns of exenatide BID usage and the accompanying outcomes in clinical practice in multiple European countries. ${ }^{26} \mathrm{CHOICE}$ was designed to assess the time to a significant treatment change after patients initiated their first injectable, glucose-lowering therapy in clinical practice. Although additional GLP-1 receptor agonists (liraglutide and exenatide once weekly) have since been approved by the European Commission, exenatide BID and insulins were the only injectable treatments available when this study commenced, hence these agents were selected for evaluation. Exenatide BID and insulin have shown similar efficacy in clinical trials, ${ }^{3-7}$ but the choice of agent is likely to be based on patient characteristics in clinical practice, and it is currently unclear which patients are prescribed exenatide BID or insulin or how long exenatide BID is prescribed before insulin is initiated. Data are also limited concerning real-world effectiveness, safety, and resource use for both GLP-1 receptor agonists and insulin. Therefore, the study also aimed to describe the characteristics of patients with T2DM initiated on injectable therapy, ${ }^{27}$ the factors associated with treatment changes, clinical and patient-reported outcomes, and the health care resource use observed over 24 months for patients who initiated exenatide BID or insulin.

This paper reports interim treatment change data and clinical outcomes during the first 12 months after the initiation of injectable therapy with exenatide BID or insulin, providing a report of the use of exenatide BID for a period beyond that investigated in most clinical trials (up to 6 months), and allowing comparison with a 12-month study of exenatide BID use in clinical practice in the USA. ${ }^{10,28}$

\section{Patients and methods}

\section{Study design and patients}

CHOICE is a prospective, multinational, noninterventional observational study that recruited patients from six European countries (Denmark, Belgium, France, Germany, Greece, and Sweden) between January 2008 and October 2009 (prior to the expanded label for exenatide BID to include adjunctive use with a thiazolidinedione or basal insulin). ${ }^{26}$ The primary endpoint of the study is the time spent on the initial injectable regimen (exenatide BID or insulin) before significant treatment change, defined as at least one of the following: addition of a new medication (any route of administration) for the treatment of T2DM, a change in the number of times 
insulin is administered per day, discontinuation of any exenatide BID/insulin initiated at baseline, or substitution of a human insulin for an analog insulin or vice versa (not including switching between brands of the same class/type of insulin). Secondary objectives of the study include identification of factors associated with the first significant treatment change, clinical outcomes (glycemic control, weight change, and changes in other cardiovascular risk factors), and reasons for discontinuation of exenatide BID or insulin. Resource use and patient-reported outcomes (including health status, health-related quality of life, locus of health control, anxiety, depression, and weight-related quality of life) were additional secondary objectives, although these are not a focus of this paper. This interim analysis focuses on the following objectives: the number of patients who reported a significant treatment change (as defined for the primary endpoint) within the first 12 months of follow-up, the reasons for this change, and clinical outcomes at 12 months. The time to significant treatment change and the factors associated with the first significant treatment change will be reported in the final analysis.

Eligible patients were aged $\geq 18$ years and initiating their first injectable glucose-lowering therapy (with exenatide BID or any type of insulin) for the treatment of T2DM in routine clinical practice. Treatment was not randomized since patients were invited to participate in CHOICE only after the clinical decision had been made to initiate exenatide BID or insulin. Physicians chose the injectable treatment to be initiated (ie, exenatide BID or insulin) following their normal treatment practice and prescribing habits. At study entry, patients could be taking any OAD. Patients gave written informed consent for the use of their data, and appropriate ethical review board approval was obtained (further details of the CHOICE study design have been published previously). ${ }^{27}$

Patients were assessed at routine study visits at the time of initiation of injectable therapy (baseline) and only when they occurred as part of clinical practice at approximately 3 , 6 , and 12 months thereafter. Patients referred from the study site to another health care provider during the study were followed-up by contacting the new provider and by postal patient questionnaires.

\section{Data collection}

At baseline (initiation of injectable therapy), standard demographic and clinical data were collected from each patient as part of their routine clinical care. ${ }^{27}$ At subsequent visits, changes to injectable therapy and the time of, and reason for, the change, were recorded. Follow-up clinical data were also collected as part of routine clinical care, including gastrointestinal (GI) adverse events, retrospectively recalled incidence of self-reported and, in most instances, self-defined hypoglycemic episodes, diabetes therapy and care, and concomitant medications.

\section{Data analysis}

\section{Sample size justification}

Based on Monte Carlo simulation and clinical data (Lilly, data on file), ${ }^{29}$ the study aimed to recruit a maximum of 800 patients per country/country group, with the expectation of approximately $60 \%$ initiating insulin and $40 \%$ initiating exenatide BID. The insulin cohort was to be larger than the exenatide BID cohort because a greater variability was anticipated in the former for the time to treatment change (linked to the use of different insulin regimens). These sample sizes were chosen to achieve a $95 \%$ confidence interval (CI) width of about 3 months ( \pm 6 weeks) around the median time to significant treatment change, a level of precision considered sufficient for descriptive purposes. ${ }^{27}$

\section{Statistical analysis}

All patients eligible at baseline (patients who provided consent to release information and who fulfilled study entry criteria), and with at least one post-baseline assessment, were included in the analyses of 12-month outcome data. Analyses were performed using all data up to the last data collection point for patients who were lost to follow-up, or who withdrew from the study. Missing data were not imputed, and analyses of outcomes at 12 months include only data available at 12 months.

Within each cohort, the number of patients who reported a significant treatment change within the 12 months of follow-up was estimated using Kaplan-Meier analysis. The reason for change in therapy was reported using descriptive statistics.

Analyses of the clinical endpoints were conducted using data from all eligible patients with at least one post-baseline assessment and with patients remaining in the cohort in which they were placed at baseline (initiators). Additional, post hoc, secondary analyses of key clinical data were conducted that considered only patients who initiated and continued on their baseline regimen without significant treatment change during the follow-up period (persisters) in case changing to a new treatment affected results.

Clinical outcomes data were reported using descriptive statistics and $95 \% \mathrm{CI}$, where appropriate, for each visit, as well as for the individual change from baseline. 
For continuous variables, mean, standard deviation (SD), and 95\% CI were calculated. Absolute numbers and percentages (including missing values) were given for categorical variables. In addition, the incidences of various composite endpoints were analyzed. Descriptive analyses were used to describe changes in exenatide or insulin dose, OADs, or concomitant medications. The incidence of GI events was also analyzed descriptively.

As previously reported, ${ }^{27}$ analysis of the baseline data (using univariate analyses and logistic regression to compare all baseline patient characteristics between the two cohorts) indicated that the two treatment cohorts comprised substantially different patient populations (Table 1). Therefore, statistical comparison of endpoints between the two cohorts was not plausible. Logistic regression was used to derive propensity scores ${ }^{30}$ using all eligible patients from the initiators' cohorts to create a matched subgroup (exenatide BID vs insulin). Patients from each cohort were matched $1: 1$ by country, based on the propensity score and optimal matching. Paired $t$-tests were used to compare changes in continuous variables, and McNemar's tests were used to compare categorical variables, using clinical data (glycemic control, body weight, BMI, waist circumference, lipids, vital signs, and hypoglycemia) from these matched patients.

Table I Baseline clinical and demographic characteristics of patients initiated on exenatide twice daily (BID) or insulin therapy for the total $\mathrm{CHOICE}$ cohort ${ }^{27}$ and propensity-matched subgroup

\begin{tabular}{|c|c|c|c|c|c|}
\hline \multirow[t]{2}{*}{ Variable } & \multicolumn{3}{|l|}{ Total cohort } & \multicolumn{2}{|c|}{ Matched subgroup ${ }^{a}$} \\
\hline & $\begin{array}{l}\text { Exenatide BID } \\
(\mathrm{n}=1177)\end{array}$ & $\begin{array}{l}\text { Insulin } \\
(n=|3| 5)\end{array}$ & $P$ & $\begin{array}{l}\text { Exenatide BID } \\
(n=570)\end{array}$ & $\begin{array}{l}\text { Insulin } \\
(n=570)\end{array}$ \\
\hline Male, n (\%) & $635(54.0)$ & $762(57.9)$ & 0.0427 & $311(54.6)$ & $330(57.9)$ \\
\hline Caucasian, n (\%) & $970(82.4)$ & 1206 (91.7) & NS & NA & NA \\
\hline Age, years & $58.0(10.1)$ & $63.7(10.9)$ & $<0.0001$ & $60.4(10.2)$ & $60.7(10.2)$ \\
\hline Weight, kg & $101.1(21.6)$ & $84.3(17.6)$ & $<0.0001$ & $92.7(17.3)$ & $92.0(17.9)$ \\
\hline $\mathrm{BMI}, \mathrm{kg} / \mathrm{m}^{2}$ & $35.3(6.5)$ & $29.7(5.4)$ & $<0.0001$ & $32.6(5.1)$ & $32.3(5.5)$ \\
\hline Waist circumference, $\mathrm{cm}$ & $114.6(14.8)$ & $103.3(14.1)$ & $<0.0001$ & $110.0(13.5)$ & $108.4(13.7)$ \\
\hline Systolic blood pressure, $\mathrm{mmHg}$ & I37.8 (16.5) & I37.4 (I7.4) & NS & $137.7(16.7)$ & I $37.5(16.5)$ \\
\hline Diastolic blood pressure, $\mathrm{mmHg}$ & $81.6(9.6)$ & $80.1(9.9)$ & $<0.0001$ & $80.6(9.5)$ & $80.5(10.2)$ \\
\hline $\begin{array}{l}\mathrm{HbA}_{\mathrm{Ic}} \text {, most recent in previous } \\
3 \text { months, \% }\end{array}$ & & $8.6(1.5)$ \\
\hline \multicolumn{6}{|l|}{ Concomitant therapy, n (\%) } \\
\hline Lipid-lowering & $664(56.4)$ & $712(54.1)$ & NS & NA & NA \\
\hline Cardiovascular & $895(76.0)$ & 972 (73.9) & NS & NA & NA \\
\hline Antiplatelet & $485(4 I .2)$ & $599(45.6)$ & NS & NA & NA \\
\hline Weight-lowering & $54(4.6)$ & $20(1.5)$ & $<0.0001$ & NA & NA \\
\hline Time since diabetes diagnosis, years & $8(6)$ & $10(7)$ & $<0.0001$ & NA & NA \\
\hline \multicolumn{6}{|c|}{ Antidiabetic medication class used (previous 12 months), $\mathrm{n}(\%)$} \\
\hline Alpha-glucosidase inhibitor & $15(1.3)$ & $2 I(I .6)$ & - & NA & NA \\
\hline Biguanide & $816(69.3)$ & $881(67.0)$ & - & NA & NA \\
\hline Biguanide + sulfonylurea & $33(2.8)$ & $39(3.0)$ & - & NA & NA \\
\hline DPP-4 inhibitor & $81(6.9)$ & $97(7.4)$ & - & NA & NA \\
\hline GLP-I receptor agonist & $2(0.2)$ & $0(0.0)$ & - & NA & NA \\
\hline $\begin{array}{l}\text { Secretion enhancer } \\
\text { (nateglinide or repaglinide) }\end{array}$ & $75(6.4)$ & $99(7.5)$ & - & NA & NA \\
\hline Sulfonylurea & $494(42.0)$ & $682(51.9)$ & - & NA & NA \\
\hline Thiazolidinedione & $136(\mid 1.6)$ & $150(\mid \mathrm{I} .4)$ & - & NA & NA \\
\hline Thiazolidinedione + biguanide & $66(5.6)$ & $39(3.0)$ & - & NA & NA \\
\hline Thiazolidinedione + sulfonylurea & $2(0.2)$ & I $(0.1)$ & - & NA & NA \\
\hline Other & $3(0.3)$ & $4(0.3)$ & - & NA & NA \\
\hline Diabetes complications, n (\%) & & & & NA & NA \\
\hline$\geq$ I macrovascular complication & $212(18.0)$ & $339(25.8)$ & $<0.000$ I & NA & NA \\
\hline$\geq$ I microvascular complication & $173(14.7)$ & $28 I(2 I .4)$ & $<0.0001$ & NA & NA \\
\hline
\end{tabular}

Notes: Continuous data presented are means (standard deviation). The Wilcoxon test was used for continuous data. The Chi-square or Fisher's exact test were used for categorical data. ${ }^{2}$ There were no statistically significant differences between the cohorts in the matched subgroup, with the exception of waist circumference $(P=0.0320)$. Abbreviations: BMI, body mass index; DPP-4, dipeptidyl peptidase-4; GLP-I, glucagon-like peptide-I; HbA ${ }_{\text {Ic }}$, glycated hemoglobin; NA, data not available; NS, nonsignificant (using a threshold for statistical significance of $P<0.05$ ). 


\section{Results}

A total of 2497 patients initiating injectable glucose-lowering therapy were recruited from a total of 325 sites across the six participating countries. Patient numbers varied by country: Belgium, 299 (43.1\% exenatide BID); Denmark, 60 (73.3\% exenatide BID); France, 295 (67.1\% exenatide BID); Germany, 848 (46.5\% exenatide BID); Greece, 807 (39.4\% exenatide BID) and Sweden, 188 (51.1\% exenatide BID); numbers reported here differ slightly from those reported previously ${ }^{27}$ because data have been updated since baseline analysis.

As comparison of baseline patient characteristics of the exenatide BID and insulin cohorts indicated that the two treatment cohorts comprised substantially different patient populations, ${ }^{27}$ statistical comparison of endpoints between the exenatide BID and insulin cohorts was not feasible. The propensity score-matched subgroup, in which exploratory between-treatment comparisons were made, included about half of the original study population and was based on baseline demographic and clinical variables (key characteristics of the total study population are summarized in Table 1).

Overall, 2335 patients had sufficient data for the 12-month analysis (ie, they had data from baseline and at least one post-baseline visit): 1096 patients in the exenatide BID cohort ( $93.0 \%$ of the baseline population) and 1239 patients in the insulin cohort ( $94.0 \%$ of the baseline population). In all countries apart from France (77.3\%) and Denmark $(81.7 \%),>90.0 \%$ of the overall baseline population was eligible for the 12-month analyses. In the exenatide BID cohort, 96 patients $(8.8 \%)$ were observed to have discontinued the study before or at the 12-month visit; this was the case for 75 patients $(6.1 \%)$ in the insulin cohort. Reasons for patients discontinuing the study are shown in Figure 1. In addition to patients observed to have discontinued, some patients included in the 12-month analyses did not have available data at the 12-month visit (but did have data at earlier times); 968 patients $(88.3 \%)$ in the exenatide BID cohort and 1128 patients $(91.0 \%)$ in the insulin cohort had data available at the 12-month visit.

\section{Treatment change}

A total of 349 patients from the exenatide BID cohort (31.8\%; Kaplan-Meier estimate at 12 months: $32.2 \%$ ) and 357 patients from the insulin cohort (28.8\%; Kaplan-Meier estimate at 12 months: $29.1 \%$ ) were observed to have a significant treatment change during the first 12 months after initiation of injectable therapy (Figure 2). Therefore, in the exenatide BID cohort, there were 1096 patients in the initiators analyses (all patients who initiated exenatide BID at baseline) and 747 patients in the persisters analyses (ie, those with no significant treatment change). Corresponding numbers in the insulin cohort were 1239 (initiators) and 882 (persisters).

At 3, 6, and 12 months, Kaplan-Meier estimates for no significant treatment change were $88.7 \%$ (95\% CI: $86.8 \%$, $90.6 \%), 79.2 \%(76.8 \%, 81.6 \%)$, and $67.8 \%(64.9 \%, 70.7 \%)$ of patients, respectively, who were initiated on exenatide BID (Figure 2). Corresponding figures for the insulin cohort were $85.5 \%$ (95\% CI: $83.5 \%, 87.5 \%$ ) of patients at 3 months, $78.0 \%(75.6 \%, 80.3 \%)$ at 6 months, and $70.9 \%(68.3 \%$, $73.5 \%$ ) at 12 months (Figure 2).

The types of treatment change and reasons for discontinuation of injectable therapy are summarized in Table 2 . In the exenatide BID cohort, 265 patients ( $24.2 \%$ of sample) added a new medication for the treatment of T2DM to their ongoing exenatide BID (for 175 patients [16.0\%], this was their first significant treatment change); overall, the most commonly added injectable therapies were long-acting insulins (insulin glargine [by $5.7 \%$ of the cohort] or insulin detemir [3.6\%]), and the most commonly added OADs were sulfonylureas (4.0\%; most frequently glimepiride [2.8\%]) and metformin (2.2\%). Of the 182 patients (16.6\%) who started insulin therapy during the first 12 months of the study, 168 (92.3\%) discontinued exenatide BID and $14(7.7 \%)$ added insulin to their ongoing exenatide BID regimen. Sulfonylureas (most commonly glimepiride) and metformin were also the most frequently discontinued OADs (by 7.1\% [glimepiride: $4.1 \%$ ] and $2.6 \%$ of the cohort, respectively).

Of the 1239 patients in the insulin cohort, $49.9 \%$ initiated insulin with long-acting insulin only, $24.5 \%$ with mixtures, $13.4 \%$ with a basal-bolus regimen, and $10.9 \%$ with shortacting insulin only ( $1.4 \%$ other or missing), although there was significant between-country variability (data not shown). During the study, 289 patients in the insulin cohort $(23.3 \%$ of the sample) added a new therapy (this was the first significant treatment change for 251 patients [20.3\%]) and 101 patients $(8.2 \%)$ discontinued their initial injectable therapy (for 80 patients [6.5\%], this was their first significant treatment change). The most commonly added injectable therapy was fast-acting insulin (by $7.6 \%$ of the insulin cohort: insulin aspart [by $3.1 \%$ of the cohort], insulin lispro [2.4\%], or insulin glulisine [2.1\%]). Overall, $5.0 \%$ of the insulin cohort added a mixture, $4.0 \%$ added long-acting insulin (insulin glargine [2.5\%] or insulin detemir [1.4\%]), and 3.9\% added 


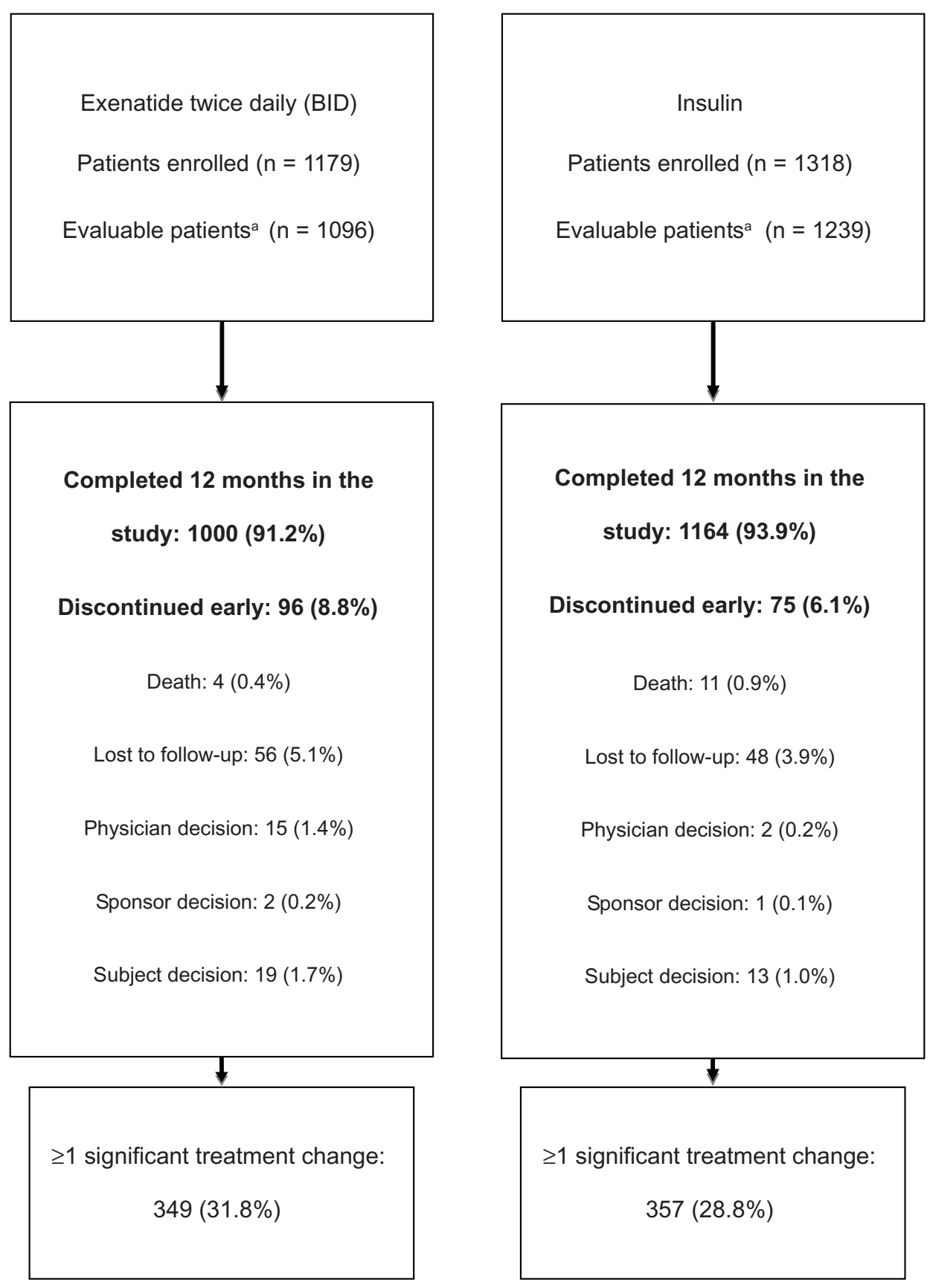

Figure I Study disposition.

Note: ${ }^{a}$ Evaluable patients were required to provide informed consent and fulfill all study entry criteria as well as have $\geq I$ post-baseline assessment.

an intermediate-acting insulin (isophane). Exenatide BID and liraglutide therapy were each initiated by two patients $(0.2 \%)$ in the insulin cohort; both patients who initiated exenatide BID continued their insulin therapy. The most commonly added and discontinued OADs were sulfonylureas (1.1\% and 6.2\%; most commonly glimepiride [0.9\% and 3.6\%, respectively]) and metformin (1.3\% and $2.7 \%$, respectively).

In the exenatide BID cohort, during the 12 months postinitiation of treatment, 287 patients (26.2\% of 1096 patients) discontinued use of the therapy - discontinuation of exenatide BID was the first significant treatment change for 269 patients (24.5\%). Adverse events were the primary stated reason for discontinuation in the first 3 months but became a less frequent reason as the study progressed $(46.0 \%$ of discontinuations in the period 0 to 3 months; $33.8 \%$ and $7.3 \%$ of discontinuations during the periods $>3$ to 6 months and $>6$ to 12 months, respectively). By contrast, inadequate response became a more common reason for discontinuing 


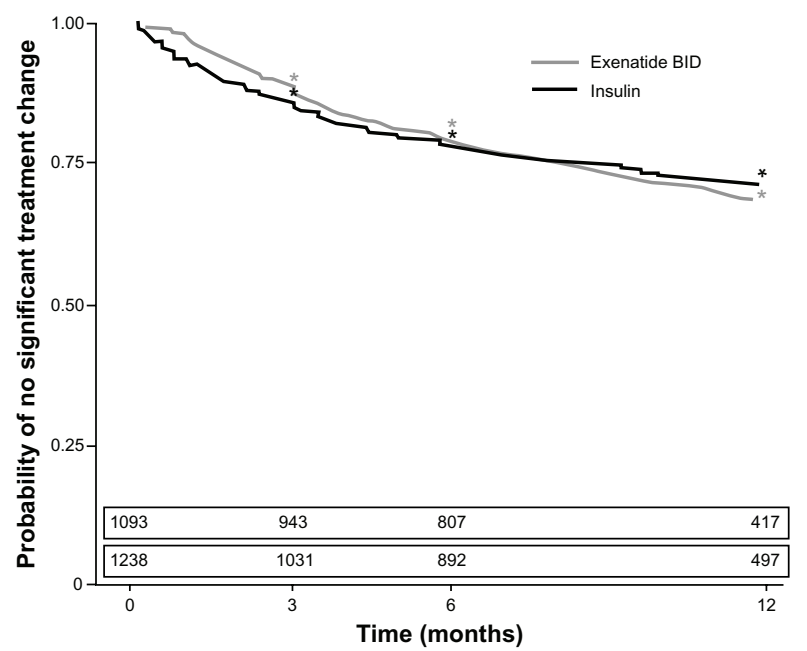

Figure 2 Kaplan-Meier estimates for time until significant treatment change after the initiation of first injectable therapy for the exenatide twice-daily (BID) cohort and total insulin cohort. The estimated number of patients remaining in the study with no significant treatment change is provided above each period.

Notes: *For exenatide BID: at 3 months, $88.7 \%$ (95\% Cl: $86.8 \%, 90.6 \%)$ of patients had no significant treatment change; at 6 months, $79.2 \%(76.8 \%, 81.6 \%)$ had no significant treatment change; at 12 months, $67.8 \%(64.9 \%, 70.7 \%)$ had no significant treatment change. For insulin: at 3 months, $85.5 \%$ (95\% Cl: $83.5 \%, 87.5 \%)$ of patients had no significant treatment change; at 6 months $78.0 \%$ (95\% Cl: 75.6\%, 80.3\%) had no significant treatment change; at 12 months $70.9 \%(68.3 \%, 73.5 \%)$ had no significant treatment change.

Abbreviation: $\mathrm{Cl}$, confidence interval.

therapy as the study progressed $(21.0 \%, 33.8 \%$, and $54.5 \%$ of discontinuations during each time period, respectively). No other trends in reasons for stopping therapy were noted.

In the insulin cohort, discontinuation of initial insulin therapy was the first significant treatment change for 80 patients $(6.5 \%$ of sample); in total, 101 patients $(8.2 \%)$ discontinued initial insulin during the 12-month study period. Inadequate response became a more frequent reason for discontinuing therapy as the study progressed $(52.8 \%$ and $50.0 \%$ of discontinuations in the periods 0 to 3 months and $>3$ to 6 months, respectively; $71.4 \%$ of discontinuations during the period $>6$ to 12 months). Adverse events in the insulin cohort were an infrequent reason for discontinuing therapy $(2.8 \%, 6.7 \%$, and $2.9 \%$ of discontinuations during each period, respectively). Long-acting insulin was the most commonly discontinued injectable by this cohort $(3.3 \%$ : insulin glargine [2.3\%] or insulin detemir [0.9\%]). Insulin mixtures were discontinued by $2.3 \%$, intermediate-acting insulin (isophane) was discontinued by $2.7 \%$, and fast-acting insulin was discontinued by $0.9 \%$ of the insulin cohort.

\section{Clinical outcomes and adverse events: exenatide BID cohort}

Glycemic control improved in the exenatide BID initiators population who had data at the 12-month visit, as shown by a mean (SD; 95\% CI) absolute reduction in $\mathrm{HbA}_{1 \mathrm{c}}$ of 1.0 $(1.4 ;-1.1,-0.9) \%$ units at 12 months, and an increase in the percentage of patients with $\mathrm{HbA}_{1 \mathrm{c}}<6.5 \%$ and $<7 \%$ from $5.5 \%$ and $9.8 \%$, respectively, at baseline to $17.1 \%$ and $33.4 \%$, respectively, at 12 months. For patients in the persisters population who had data at the 12 -month visit, the mean (SD; 95\% CI) reduction in $\mathrm{HbA}_{1 \mathrm{c}}$ was $1.2(1.4 ;-1.3,-1.0) \%$ units at 12 months. At this time, the percentage of patients with $\mathrm{HbA}_{1 \mathrm{c}}<6.5 \%$ and $<7 \%$ was $19.9 \%$ and $37.9 \%$, respectively. Of the 947 patients in the exenatide BID cohort with $\mathrm{HbA}_{1 \mathrm{c}} \geq 7 \%$ at baseline, $18.8 \%$ had $\mathrm{HbA}_{1 \mathrm{c}}<7 \%$ at both the 6- and 12-month visits, $9.4 \%$ had $\mathrm{HbA}_{1 \mathrm{c}} \geq 7 \%$ at the 6-month visit but had achieved $\mathrm{HbA}_{1 \mathrm{c}}<7 \%$ at the 12 -month visit, and $9.1 \%$ had $\mathrm{HbA}_{1 \mathrm{c}}<7 \%$ at the 6-month but not the 12-month visit; $40.3 \%$ of patients did not achieve $\mathrm{HbA}_{1 \mathrm{c}}$ $<7 \%$ at either the 6 - or 12 -month visit.

Patients in the exenatide BID initiators population who provided data at the 12-month visit had improvements in a number of cardiovascular risk factors, including mean body weight, BMI, waist circumference, blood pressure (BP), and lipid parameters at this time (Table 3 ).

Weight loss $(>1.0 \mathrm{~kg})$ was achieved by $64.7 \%$ of exenatide BID initiators who had data at 12 months; $2.9 \%$ had minimal change in body weight $(\leq 1.0 \mathrm{~kg}$ weight gain or loss) and $15.9 \%$ had weight gain $(>1.0 \mathrm{~kg})$ by month 12 . In the persisters population with data at 12 months, $70.7 \%$ of patients achieved a weight loss of $>1.0 \mathrm{~kg}$, with $3.5 \%$ having minimal change in body weight and $11.0 \%$ having weight gain by month 12 . Mean (SD; 95\% CI) weight change from baseline to 12 months was $-3.3(5.9 ;-3.7,-2.9) \mathrm{kg}$ and -4.2 $(5.6 ;-4.6,-3.8) \mathrm{kg}$ for initiators and persisters, respectively.

Overall, hypoglycemia was experienced by $13.2 \%$ of patients who initiated exenatide BID (12.4\% of the persisters population), with $2.2 \%$ of patients experiencing nocturnal hypoglycemia (Table 4). Of patients who experienced hypoglycemia, most $(82.8 \%)$ were receiving concomitant sulfonylureas (see Table 4).

In a post hoc analysis, at 12 months after initiation of exenatide BID, $24.3 \%$ of the initiators population and $28.9 \%$ of the persisters population were observed to have met the composite endpoint of $\mathrm{HbA}_{1 \mathrm{c}}<7 \%$, no weight gain ( $\leq 1 \mathrm{~kg}$ change), and no hypoglycemia. In the initiators population, 159 patients $(14.5 \%)$ could not be assessed for this endpoint because data were missing for some parameters (available parameters may have fulfilled the criteria), and 35 patients $(3.2 \%)$ had missing data for all parameters.

The incidences of total and individual GI events are presented in Table 5. Overall, 27.8\% of the exenatide BID 
Table 2 Treatment change occurring during the 12 months following initiation of exenatide twice daily (BID) and insulin in patients with type 2 diabetes mellitus ${ }^{\mathrm{a}}$

\begin{tabular}{|c|c|c|}
\hline Variable & $\begin{array}{l}\text { Exenatide BID } \\
(n=1096)\end{array}$ & $\begin{array}{l}\text { Insulin } \\
(n=1239)\end{array}$ \\
\hline$\geq$ I significant treatment change, $n(\%)$ & $349(31.8)$ & $357(28.8)$ \\
\hline \multicolumn{3}{|l|}{ First significant treatment change, $n$ (\%) } \\
\hline Addition of a new medication (any route of administration) & $175(16.0)$ & $251(20.3)$ \\
\hline \multicolumn{3}{|l|}{ for the treatment of type 2 diabetes $^{b}$} \\
\hline Addition of a new oral medication & $86(7.8)$ & $44(3.6)$ \\
\hline Addition of a new injectable medication & $96(8.8)$ & $208(16.8)$ \\
\hline Change to the number of times insulin was administered per day & NA & $71(5.7)$ \\
\hline Substitution of a human insulin for an analog insulin or vice versa & NA & $17(1.4)$ \\
\hline Discontinuation of any injectable medication initiated at baseline & $269(24.5)$ & $80(6.5)$ \\
\hline \multicolumn{3}{|l|}{ Any significant treatment change, $n(\%)$} \\
\hline Addition of a new medication (any route of administration) & $265(24.2)$ & $289(23.3)$ \\
\hline \multicolumn{3}{|l|}{ for the treatment of type 2 diabetes } \\
\hline Addition of a new oral medication & $115(10.5)$ & $60(4.8)$ \\
\hline Addition of a new injectable medication & $182(16.6)$ & $244(19.7)$ \\
\hline Change to the number of times insulin was administered per day & NA & $94(7.6)$ \\
\hline Substitution of a human insulin for an analog insulin or vice versa & NA & $25(2.0)$ \\
\hline Discontinuation of any injectable medication initiated at baseline ${ }^{c}$ & $287(26.2)$ & $101(8.2)$ \\
\hline \multicolumn{3}{|l|}{ Reasons for discontinuation, $\mathrm{n}(\%)$} \\
\hline Inadequate response & $107(9.8)$ & $59(4.8)$ \\
\hline Adverse event & $80(7.3)$ & $4(0.3)$ \\
\hline Noncompliance & $7(0.6)$ & $2(0.2)$ \\
\hline Subject decision & $49(4.5)$ & $12(1.0)$ \\
\hline Cannot afford medication & $4(0.4)$ & $I(0.1)$ \\
\hline Other & $40(3.6)$ & $23(1.9)$ \\
\hline
\end{tabular}

cohort experienced GI adverse events at some time during the study, as recorded for the 4-week period before each visit. Notably, the incidence of GI events decreased over time (Figure 3). Of the 275 GI symptoms experienced in the period 0 to 3 months, $59.3 \%$ were experienced daily or on most days, whereas $41.6 \%$ of the 149 symptoms occurring in the period 3 to 6 months and $32.6 \%$ of the 86 symptoms occurring in the period 6 to 12 months occurred daily or on most days. However, GI symptoms were often not associated with meals ( $44.1 \%$ of all events), causing only $17.6 \%$ of affected patients to miss $\geq 1$ meal during the study.

\section{Clinical outcomes and adverse events: insulin cohort}

Glycemic control improved in the insulin initiators population with data available at the 12 -month visit, as shown by a mean (SD; 95\% CI) absolute reduction in $\mathrm{HbA}_{1 \mathrm{c}}$ of $1.8(1.8 ;-1.9$, $-1.7) \%$ units at 12 months (Figure 4 ) and an increase in the percentage of patients with $\mathrm{HbA}_{1 \mathrm{c}}<6.5 \%$ and $<7 \%$ from $3.3 \%$ and $5.1 \%$, respectively, at baseline to $14.5 \%$ and $32.2 \%$, respectively, at 12 months. Similar improvements in glycemic control were seen in the persisters population with data at the 12 -month visit: the mean $(\mathrm{SD} ; 95 \% \mathrm{CI})$ reduction in $\mathrm{HbA}_{1 \mathrm{c}}$ was $1.8(1.8 ;-1.9,-1.6) \%$ units at 12 months, and $14.5 \%$ and $31.4 \%$ of patients had $\mathrm{HbA}_{1 \mathrm{c}}<6.5 \%$ and $<7 \%$, respectively, at this time. Improvements in glycemic control did not appear to differ substantially according to the insulin regimen initiated at baseline (Figure 4). Of the 1142 patients in the insulin cohort with $\mathrm{HbA}_{1 \mathrm{c}} \geq 7 \%$ at baseline, $20.2 \%$ had $\mathrm{HbA}_{1 \mathrm{c}}<7 \%$ at both the 6- and 12-month visits, $8.8 \%$ had $\mathrm{HbA}_{1 \mathrm{c}} \geq 7 \%$ at the 6-month visit but had achieved $\mathrm{HbA}_{1 \mathrm{c}}<7 \%$ at the 12-month visit, and $8.7 \%$ had $\mathrm{HbA}_{1 \mathrm{c}}$ $<7 \%$ at the 6-month but not the 12-month visit; $42.3 \%$ of patients did not achieve $\mathrm{HbA}_{1 \mathrm{c}}<7 \%$ at either the 6- or 12-month visit.

The mean (SD; 95\% CI) body weight of patients in the insulin initiators and persisters populations with data available at 12 months increased between baseline and 12 months (by $1.9[4.9 ; 1.6,2.1] \mathrm{kg}$ and $1.8[4.7 ; 1.4,2.1] \mathrm{kg}$, respectively). A greater mean weight gain was seen in patients receiving short-acting only $(2.8 \mathrm{~kg})$ or basal-bolus $(2.4 \mathrm{~kg})$ regimens and a lower mean weight gain was seen in those receiving 
Table 3 Mean changes in clinical variables from baseline to 12 months (for patients with data at 12 months) after initiation of exenatide twice daily (BID) or insulin in patients with type 2 diabetes mellitus - initiators population

\begin{tabular}{|c|c|c|}
\hline Variable & Exenatide BID & Insulin \\
\hline $\mathrm{HbA}_{\mathrm{Ic}}, \mathrm{n}$ & 871 & 1009 \\
\hline$\%$ units (SD; 95\% Cl) & $-1.0(1.4 ;-1.1,-0.9)$ & $-1.8(1.8 ;-1.9,-1.7)$ \\
\hline Body weight, $\mathrm{n}$ & 915 & 1045 \\
\hline kg (SD; 95\% Cl) & $-3.3(5.9 ;-3.7,-2.9)$ & $1.9(4.9 ; 1.6,2.1)$ \\
\hline \multicolumn{3}{|c|}{ Body weight according to insulin type, $\mathrm{kg}(\mathrm{SD} ; 95 \% \mathrm{Cl}$ ) } \\
\hline Basal bolus $(n=166)$ & NA & $2.4(6.5 ; 1.3,3.5)$ \\
\hline Long acting only $(n=6 \mid 8)$ & NA & $1.6(4.2 ; 1.2,1.9)$ \\
\hline Mixtures only $(n=303)$ & NA & I.8 (5.2; I.2, 2.4) \\
\hline Short acting only $(n=135)$ & NA & $2.8(4.8 ; 1.9,3.6)$ \\
\hline Other $(n=14)$ & NA & $1.3(4.4 ;-1.6,4.3)$ \\
\hline BMI, $n$ & 906 & 1042 \\
\hline $\mathrm{kg} / \mathrm{m}^{2}(\mathrm{SD} ; 95 \% \mathrm{Cl})$ & $-1.2(2.1 ;-1.3,-1.0)$ & $0.7(1.7 ; 0.6,0.8)$ \\
\hline Waist circumference, $\mathrm{n}$ & 651 & 742 \\
\hline $\mathrm{cm}(\mathrm{SD} ; 95 \% \mathrm{Cl})$ & $-2.5(8.9 ;-3.2,-1.8)$ & I.4 (9.0; 0.7, 2.0) \\
\hline Blood pressure, $n$ & 858 & 963 \\
\hline Systolic, mmHg (SD; 95\% Cl) & $-2.4(17.2 ;-3.6,-1.3)$ & $-2.5(18.5 ;-3.6,-1.3)$ \\
\hline Diastolic, mmHg (SD; 95\% Cl) & $-1.6(10.8 ;-2.3,-0.8)$ & $-1.8(11.1 ;-2.5,-1.1)$ \\
\hline \multicolumn{3}{|l|}{ Plasma lipids, mmol/L (SD; 95\% Cl) } \\
\hline \multirow[t]{2}{*}{ Total cholesterol, $\mathrm{n}$} & 692 & 789 \\
\hline & $-0.2(1.0 ;-0.3,-0.1)$ & $-0.3(I .1 ;-0.3,-0.2)$ \\
\hline \multirow[t]{2}{*}{ LDL cholesterol, $\mathrm{n}$} & 640 & 733 \\
\hline & $-0.1(0.9 ;-0.2,-0.0)$ & $-0.2(0.9 ;-0.3,-0.1)$ \\
\hline \multirow[t]{2}{*}{ HDL cholesterol, $n$} & 658 & 753 \\
\hline & $0.0(0.3 ; 0.0,0.1)$ & $0.1(0.3 ; 0.0,0.1)$ \\
\hline \multirow[t]{2}{*}{ Triglycerides, $\mathrm{n}$} & 675 & 773 \\
\hline & $-0.3(1.4 ;-0.4,-0.2)$ & $-0.4(1.6 ;-0.5,-0.3)$ \\
\hline
\end{tabular}

Note: Continuous data are means (SD; $95 \% \mathrm{Cl})$.

Abbreviations: BMI, body mass index; $\mathrm{Cl}$, confidence interval; $\mathrm{HbA}_{\mathrm{Ic}}$, glycated hemoglobin; $\mathrm{HDL}$, high-density lipoprotein; LDL, low-density lipoprotein; $\mathrm{NA}$, not applicable; $\mathrm{SD}$, standard deviation.

mixtures $(1.8 \mathrm{~kg})$ or long-acting agents only $(1.6 \mathrm{~kg}$; see Table 3). A total of $33.3 \%$ of patients initiated on insulin therapy achieved weight loss $(>1.0 \mathrm{~kg})$, whereas $5.2 \%$ had minimal change in body weight and $45.9 \%$ had weight gain $(>1.0 \mathrm{~kg}$ ) by month 12 . Similarly, $32.9 \%$ of patients remaining in the insulin cohort without significant treatment change and with data available at 12 months achieved weight loss, with $5.4 \%$ having minimal change in body weight and $44.2 \%$ having weight gain by month 12 . At 12 months, patients in the insulin cohort also had improvements in mean BP and lipid parameters (see Table 3).

Overall, $28.6 \%$ of patients who initiated insulin therapy were observed to have experienced hypoglycemia in the first 12 months after initiation (see Table 4), with the incidence being highest in patients initiated on mixtures only (40.3\%) or a basal-bolus regimen $(33.1 \%$; the 14 patients receiving "other" regimens had an incidence of 50.0\%). Lower rates of hypoglycemia were reported in patients initiated on longacting only $(23.0 \%)$ or short-acting only $(20.7 \%)$ regimens. Overall, 55.6\% of patients who reported hypoglycemia were receiving sulfonylureas. Nocturnal hypoglycemia was reported in $11.3 \%$ of patients initiated on insulin (see Table 4).

At 12 months after initiation of first insulin therapy, $10.3 \%$ of the initiators population and $10.9 \%$ of the persisters population were observed to have met the composite endpoint of $\mathrm{HbA}_{1 \mathrm{c}}<7 \%$, no weight gain ( $\leq 1 \mathrm{~kg}$ change), and no hypoglycemia. In the initiators population, 147 patients (11.9\%) could not be assessed for this endpoint because data were missing for some parameters (available parameters may have fulfilled the criteria), and 22 patients (1.8\%) had missing data for all parameters.

The incidences of total and individual GI events are presented in Table 5. Overall, 3.5\% of the insulin cohort reported GI adverse events.

\section{Clinical outcomes and adverse events: matched subgroup analysis}

Propensity matching on baseline clinical and demographic variables, and country of participation, identified 1140 patients (570 from each cohort) who could be matched and compared at 12 months (Table 1 presents data for the 
Table 4 Hypoglycemia occurring between baseline and 12 months (or time of study discontinuation, if earlier than 12 months) after initiation of exenatide twice daily (BID) or insulin in patients with type 2 diabetes mellitus - initiators population

\begin{tabular}{|c|c|c|}
\hline Variable & Exenatide BID $(n=1096)$ & Insulin $(n=1239)$ \\
\hline \multicolumn{3}{|l|}{ Patients with $\geq$ I hypoglycemic event, n (\%) } \\
\hline Total & $145(13.2)$ & $354(28.6)$ \\
\hline Nocturnal hypoglycemia & $24(2.2)$ & $140(11.3)$ \\
\hline Daytime hypoglycemia & $13 \mid(12.0)$ & $318(25.7)$ \\
\hline Events resolved by patient alone & $140(12.8)$ & $345(27.8)$ \\
\hline Total events requiring third-party assistance but not hospitalization & $5(0.5)$ & $50(4.0)$ \\
\hline Events requiring a visit to the emergency room & $2(0.2)$ & $8(0.6)$ \\
\hline Events requiring admission to hospital & $2(0.2)$ & $7(0.6)$ \\
\hline Severe hypoglycemia ${ }^{a}$ & $7(0.6)$ & $54(4.4)$ \\
\hline Patients receiving sulfonylureas & $(n=587)$ & $(n=602)$ \\
\hline Patients with $\geq$ I hypoglycemic event, (\%) & $120(20.4)$ & $197(32.7)$ \\
\hline Patients not receiving sulfonylureas & $(n=509)$ & $(n=637)$ \\
\hline Patients with $\geq$ I hypoglycemic event, $\mathrm{n}(\%)$ & $25(4.9)$ & $157(24.6)$ \\
\hline \multicolumn{3}{|c|}{ Number of hypoglycemic events among patients with $\geq I$ episode, mean (SD; 95\% CI) } \\
\hline Total & $6.0(8.5 ; 4.6,7.5)^{\mathrm{b}}$ & $7.7(21.8 ; 5.4,10.0)^{c}$ \\
\hline Nocturnal hypoglycemia & $2.6(3.5 ; \mathrm{I} . \mathrm{I}, 4 . \mathrm{I})$ & $2.8(3.1 ; 2.3,3.3)$ \\
\hline Daytime hypoglycemia & $6.1(8.5 ; 4.6,7.5)$ & $7.2(22.2 ; 4.7,9.6)$ \\
\hline Events resolved by patient alone & $6.1(8.5 ; 4.6,7.5)$ & $7.4(21.8 ; 5.1,9.7)$ \\
\hline Events requiring third-party assistance but not hospitalization & $1.6(1.3 ;-0.1,3.3)$ & $1.8(1.6 ; 1.3,2.3)$ \\
\hline Events requiring a visit to the emergency room & $1.0(0.0 ;-)$ & I.I $(0.4 ; 0.8, I .4)$ \\
\hline Events requiring admission to hospital & $1.0(0.0 ;-)$ & $1.0(0.0 ;-)$ \\
\hline Severe hypoglycemia ${ }^{\mathrm{a}}$ & $1.7(I . I ; 0.7,2.7)$ & $2.0(1.6 ; 1.5,2.4)$ \\
\hline In patients receiving sulfonylureas & $6.0(8.4 ; 4.5,7.5)$ & $5.9(7.5 ; 4.8,7.0)$ \\
\hline In patients not receiving sulfonylureas & $6.2(9.0 ; 2.4,10.0)$ & $9.9(31.4 ; 4.9,14.9)$ \\
\hline \multicolumn{3}{|l|}{ Rate of hypoglycemic events in each treatment cohort } \\
\hline Number per 100 patients per 30 days (SD; $95 \% \mathrm{Cl})$ & $7.4(36.2 ; 5.5,10.3)$ & $19.5(\mid 25.1 ;$ I4.9, 33.4) \\
\hline
\end{tabular}

Abbreviations: $\mathrm{Cl}$, confidence interval; SD, standard deviation.

matched groups). In this population, for patients with data available at 12 months, there was no significant difference between the treatment-matched groups (exenatide BID vs insulin) in mean (SD) change in $\mathrm{HbA}_{1 \mathrm{c}}(-1.25[1.48] \%$ units vs -1.31 [1.52] \% units; $P=0.738 ; \mathrm{n}=454$ vs 477 ) or in the percentage of patients at 12 months with $\mathrm{HbA}_{1 \mathrm{c}}<7 \%$ (31.1\% vs $36.5 \% ; P=0.265$, McNemar's test; $\mathrm{n}=461$ vs $489)$ or $<6.5 \%(15.3 \%$ vs $15.4 \% ; P=0.863$, McNemar's test; $n=461$ vs 489). However, patients in the exenatide BID matched group had significantly greater mean (SD) weight loss (change: -2.7 [5.2] kg vs +1.6 [4.8] kg; $P<0.0001$; $\mathrm{n}=478$ vs 494 ), BMI reduction (change: $-0.9[1.9] \mathrm{kg} / \mathrm{m}^{2}$ vs $\left.+0.6[1.7] \mathrm{kg} / \mathrm{m}^{2} ; P<0.0001 ; \mathrm{n}=471 \mathrm{vs} 494\right)$ and waist circumference reduction (change: -2.0 [8.9] $\mathrm{cm}$ vs +0.8 [6.3] cm; $P<0.0001 ; \mathrm{n}=340$ vs 358 ) compared with the insulin matched group. The incidence of hypoglycemia during the study was lower in the exenatide BID matched group than the insulin matched group $(15.1 \%$ vs $24.6 \%$; $P<0.0001$, McNemar's test; $\mathrm{n}=551$ vs 566). Mean changes (exenatide BID vs insulin) in total cholesterol $(-0.3[1.0] \mathrm{mmol} / \mathrm{L}$ vs -0.2 [1.2] $\mathrm{mmol} / \mathrm{L})$, high-density lipoprotein cholesterol (HDL; +0.0 [0.3] $\mathrm{mmol} / \mathrm{L}$ vs $+0.1[0.4] \mathrm{mmol} / \mathrm{L})$, low-density lipoprotein cholesterol (LDL; -0.1 [0.9] mmol/L vs -0.2 [0.9] $\mathrm{mmol} / \mathrm{L})$, triglyceride $(-0.4[1.3] \mathrm{mmol} / \mathrm{L}$ vs $-0.3[1.3] \mathrm{mmol} / \mathrm{L})$, and BP (systolic: -2.7 [17.2] $\mathrm{mmHg}$ vs -2.7 [18.3] $\mathrm{mmHg}$; diastolic: -1.1 [10.6] $\mathrm{mmHg}$ vs -1.6 [11.3] $\mathrm{mmHg}$ ) levels did not differ significantly between the two matched groups ( $n=332$ to 445 patients per exenatide BID group and $n=342$ to 460 per insulin group depending on endpoint of interest).

\section{Discussion}

This prospective observational study was designed to evaluate patterns of exenatide BID and insulin usage (in particular, treatment changes post-initiation) and outcomes in clinical practice in multiple European countries. We selected time to significant treatment change as the primary endpoint of the study to improve understanding of when and how treatment 
Table 5 Gastrointestinal ( $\mathrm{Gl}$ ) events occurring during the 12 months (or time of study discontinuation, if earlier than 12 months) following initiation of exenatide twice daily (BID) and insulin in patients with type 2 diabetes mellitus - initiators population

\begin{tabular}{|c|c|c|}
\hline Variable & $\begin{array}{l}\text { Exenatide BID } \\
(\mathrm{n}=1096)\end{array}$ & $\begin{array}{l}\text { Insulin } \\
(n=1239)\end{array}$ \\
\hline $\begin{array}{l}\text { Patients with } \geq \text { I Gl symptom, } \\
\mathrm{n}(\%)\end{array}$ & $305(27.8)$ & $43(3.5)$ \\
\hline I symptom & $186(17.0)$ & $28(2.3)$ \\
\hline 2 symptoms & $67(6.1)$ & $8(0.6)$ \\
\hline 3 symptoms & $29(2.6)$ & $5(0.4)$ \\
\hline$\geq 4$ symptoms & $23(2.1)$ & $2(0.2)$ \\
\hline \multicolumn{3}{|l|}{ Type of Gl event, $n$ (\%) } \\
\hline Nausea & $165(15.1)$ & $7(0.6)$ \\
\hline Abdominal pain & $62(5.7)$ & $2 \mathrm{I}(\mathrm{I} .7)$ \\
\hline Fullness/early satiety & $68(6.2)$ & $5(0.4)$ \\
\hline Vomiting & $62(5.7)$ & $3(0.2)$ \\
\hline Heartburn & $4 \mid(3.7)$ & $15(1.2)$ \\
\hline Anorexia & $22(2.0)$ & $\mathrm{I}(0.1)$ \\
\hline Taste changes & II (I.0) & $\mathrm{I}(0 . \mathrm{I})$ \\
\hline
\end{tabular}

with exenatide BID and insulin is amended post-baseline, since changes in therapy are often associated with increased use of resources (particularly clinician's time), device changes, and uncertainty for patients. Overall, 31.8\% (Kaplan-Meier estimate: $32.2 \%$ ) of patients who initiated exenatide BID as their first injectable glucose-lowering therapy had a significant treatment change $(24.2 \%$ of the total exenatide BID cohort added to exenatide BID and $26.2 \%$ discontinued exenatide BID) during the first 12 months of therapy. The corresponding change value for patients whose first initiated injectable glucose-lowering therapy was insulin was $28.8 \%$ (KaplanMeier estimate: $29.1 \%$ ), with most patients adding a new therapy for T2DM, most commonly a short-acting insulin. Discontinuations accounted for only a small proportion of the treatment changes in the insulin cohort $(8.2 \%$ overall);

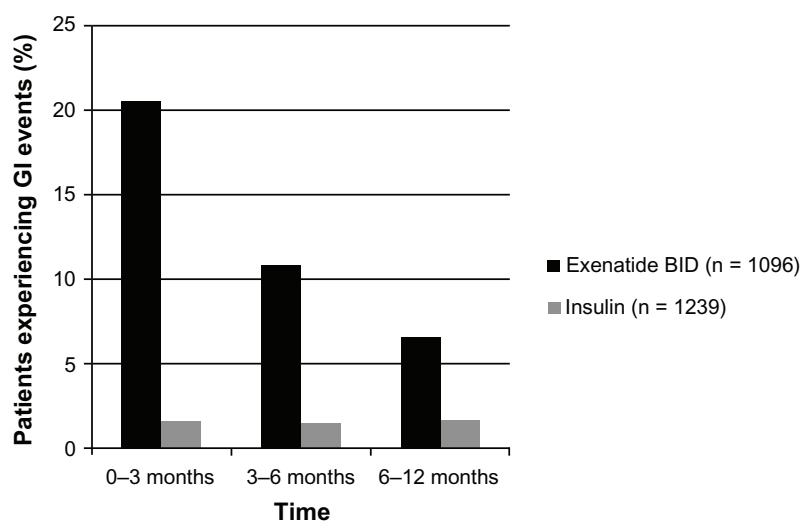

Figure 3 The incidence of gastrointestinal ( $\mathrm{Gl}$ ) events after initiation of exenatide twice daily (BID) or insulin in patients with type 2 diabetes mellitus.

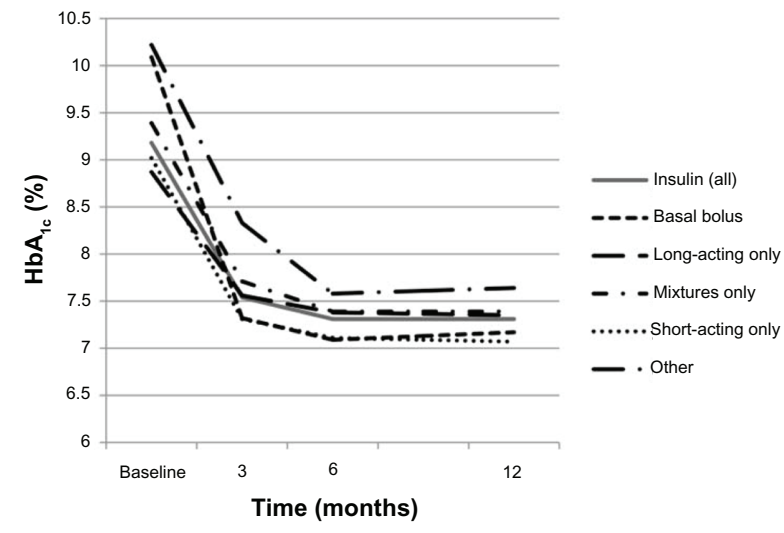

Figure 4 Change in glycated hemoglobin $\left(\mathrm{HbA}_{1 \mathrm{c}}\right)$ according to the type of first insulin therapy initiated during the 12 months following initiation of that therapy.

inadequate response became a more frequent reason for discontinuing therapy as the study progressed.

We considered the rate of change in therapy for patients initiated on insulin in the CHOICE study to be relatively high, particularly when compared with similar prospective European observational studies considering treatment change post-insulin initiation, ${ }^{31,32}$ and to be driven primarily by the addition of a new agent rather than discontinuing the initial therapy. In the other studies, $12 \%$ of patients changed their insulin regimen at 12 months, ${ }^{31}$ and $2.9 \%$ to $19.4 \%$ of patients changed, depending on insulin regimen, at 24 months. ${ }^{32}$ As similar proportions of patients were initiated on long-acting insulin (50\% vs $45 \%$ and $50 \%$ ) and the mean time since diabetes diagnosis was similar (10 years for each study) in the CHOICE insulin cohort and these other European studies, ${ }^{31,32}$ we are unable to explain this finding. However, retrospective database analyses have reported wide ranges of persistence rates with insulin therapy, some of which were similar to or lower than those we report here at $6(75 \% \text { overall })^{33}$ and 12 months (66\%-92\%, depending on insulin type; no results for the total insulin group were reported). ${ }^{34,35}$

The rate of treatment change appeared to be relatively stable throughout the 12-month study period in the exenatide BID cohort. It should be noted that the primary reason for discontinuation of exenatide BID in the first 3 months of the study was adverse events (assumed to be GI-related), whereas the primary reason towards the end of the 12-month follow-up was lack of efficacy. By contrast, significant treatment change occurred at almost twice the later rate during the first 3 months of the study in the insulin cohort (14.5\%, compared with $7.5 \%$ and $7.1 \%$ during the periods $>3$ to 6 months and $>6$ to 12 months, respectively).

CHOICE considered patients initiating exenatide BID or insulin in routine clinical practice. Unlike the situation in 
randomized trials, compared with patients initiated on insulin, patients initiated on exenatide BID in CHOICE tended to have a younger age; higher body weight, BMI, waist circumference, and diastolic BP; lower total and LDL-cholesterol levels; a shorter time since diabetes diagnosis; and better glycemic control at baseline. ${ }^{27}$ These differences are consistent with observational data from the Exenatide BID Observational Study (ExOS) in the USA. ${ }^{10,11}$ However, other studies have supported the use of exenatide $\mathrm{BID}$ at various ranges of $\mathrm{HbA}_{1 \mathrm{c}}$, including high values $(>9 \%) \cdot{ }^{36-38}$ It is also possible that exenatide BID is used earlier in T2DM to intensify therapy, thereby delaying the need for insulin initiation.

Randomized clinical trials have shown that GLP-1 receptor agonists are at least as effective as insulin therapy, and are usually associated with weight loss. ${ }^{3-5,7,8}$ However, the observed differences in the patient populations in CHOICE make it difficult to compare the exenatide BID and insulin cohorts in a statistically meaningful manner. It should be noted that clinical findings pertaining to $\mathrm{HbA}_{1 \mathrm{c}}$ and weight for the initiators and persisters populations in both the exenatide BID and insulin cohorts of CHOICE were similar to those obtained in clinical trials evaluating exenatide BID $^{3,4,6,36,37,39,40}$ and a range of insulin regimens. ${ }^{41-43}$ At 12 months after initiation of injectable therapy, $24.3 \%$ and $28.9 \%$ of the initiators and persisters population, respectively, from the exenatide BID cohort, and about $10 \%$ of both populations from the insulin cohort, met the clinically relevant composite endpoint suggested by Zinman and colleagues ${ }^{44}$ of $\mathrm{HbA}_{1 \mathrm{c}}<7 \%$, no weight gain ( $\leq 1 \mathrm{~kg}$ change), and no hypoglycemia. Analysis using initiators compared with persisters evaluable populations had little or no effect on outcomes in the insulin cohort and little effect in the exenatide BID cohort; if anything, there was a slight tendency for outcomes to be improved in the persisters compared with the initiators exenatide BID population. This observation is reassuring, as outcomes in the persisters population represent likely findings in patients actually receiving the initial injectable treatment, whereas the initiators populations better represent an intention-to-treat population that included patients who were receiving an alternative or additional treatment by 12 months.

To allow direct comparison of outcomes between the two treatment cohorts, we performed a matched subgroup analysis, which focused on the cardio-metabolic parameters that are currently a target of treatment: glycemic control while avoiding hypoglycemia, BP control, LDL-cholesterol control, and weight. ${ }^{45}$ This analysis showed that, in common with findings of clinical trials, ${ }^{43}$ patients in the exenatide BID matched group had greater weight loss and a lower risk of hypoglycemia than patients in the insulin matched group, although glycemic control $\left(\mathrm{HbA}_{1 \mathrm{c}}\right.$ change and the proportion of patients with $\mathrm{HbA}_{1 \mathrm{c}}<7 \%$ or $<6.5 \%$ ) and changes in LDL cholesterol did not differ. However, these findings should be interpreted with caution because less than half of the patients with 12 -month data (48.8\%) were included in the propensity-matched analyses. CHOICE was not designed to compare the treatment groups since different patient characteristics, as anticipated, appear to have resulted in different treatment allocations. In particular, patients in the exenatide BID matched group tended to be older, have poorer $\mathrm{HbA}_{1 \mathrm{c}}$ control, and lower body weight than the full exenatide BID cohort, and patients from the insulin matched group tended to be younger and have better control of $\mathrm{HbA}_{1 \mathrm{c}}$, and higher body weight than the full insulin cohort.

The CHOICE study has provided the first available data on the way exenatide BID is used in routine clinical practice across Europe. However, in common with all prospective observational studies, this study has limitations. These include the potential for unobserved factors that could have affected treatment selection or outcomes, the potential for investigators to be influenced by the scrutiny that occurs during a prospective study and the potential for bias - although the inclusion of two treatment arms should have helped to reduce prescribing bias. In addition, although the sample was designed to be representative, sample sizes were small in some countries, the ratio of exenatide BID to insulin patients varied between countries, and patients were mostly recruited in secondary care centers. Also, there may be significant unmeasured confounding factors we were unable to control for in the subgroup comparison of cohorts, and we used non-standardized measurements to assess clinical outcomes, including hypoglycemia, which relied on patient recall and self-reporting of episodes that did not have standardized diagnoses. The inclusion of several European countries may also have resulted in variations in diabetes care, including access to self-monitoring of blood glucose and the types of insulin initiated at different sites. Thus, the extent to which data can be generalized is not clear. It is also likely that treatment patterns will change to some extent following the March 2012 European Union approval of exenatide BID as adjunctive therapy in adult patients with T2DM who have not achieved adequate glycemic control with basal insulin, with or without metformin and/or pioglitazone. ${ }^{23}$ Although not an approved indication for exenatide BID during the study period described here, and only two patients from the insulin cohort were initiated on this agent during the study, we expect that this new indication for exenatide BID may have a substantial impact on prescribing trends for patients with T2DM, as UK-based 
audits have shown that many of the patients initiated on GLP-1 receptor agonists before this indication was approved (between 30\% and 40\%) were also receiving basal insulin concomitantly. ${ }^{12,46}$ Similarly, the availability of liraglutide and exenatide once weekly has likely affected treatment patterns subsequent to these data being collected.

\section{Conclusion}

In addition to estimating the number of patients with significant treatment change and evaluating reasons for the treatment change following initiation of injectable therapy, CHOICE provided data on exenatide BID and insulin usage patterns and 12-month outcomes in clinical practice. Results show that about $30 \%$ of patients initiated on exenatide BID or insulin as their first injectable glucose-lowering therapy had a significant treatment change during the first 12 months of therapy.

Overall, both cohorts achieved improved glycemic control (in terms of mean $\mathrm{HbA}_{1 \mathrm{c}}$ change and the proportion of patients achieving $\mathrm{HbA}_{1 \mathrm{c}}<7 \%$ or $<6.5 \%$ ) and a reduced severity of cardiovascular risk factors, which included a mean weight loss in the exenatide BID cohort. There was a mean weight gain in the insulin cohort. The matched subgroup analysis found that, although patients in the two matched groups achieved similar glycemic control, patients in the exenatide BID matched group had a significantly lower incidence of hypoglycemia and greater weight loss than patients in the insulin matched group. Changes in total, HDL and LDL-cholesterol, triglyceride, and BP levels did not differ significantly between the matched groups.

\section{Acknowledgment}

The authors would like to acknowledge Caroline Spencer, Lee Baker, and Claire Lavin (Rx Communications, Mold, UK) for medical writing assistance with the preparation of this article, funded by Eli Lilly.

\section{Disclosure}

The study and the development of this manuscript were sponsored by Eli Lilly and Amylin Pharmaceuticals. The sponsors and authors were involved in the decision to submit the manuscript for publication in Diabetes, Metabolic Syndrome and Obesity: Targets and Therapy. The authors maintained complete control over the direction and content of the manuscript and did not receive financial compensation for its development.

Stephan Matthaei and Bruno Guerci have received honoraria from Eli Lilly for lectures and consultancy. Claes-Göran Östenson has received honoraria from Eli Lilly for consultancy.
Chantal Mathieu is an advisory board member for Lilly Belgium. Thure Krarup is an advisory board member for Lilly Denmark. Matthew Reaney, Jacek Kiljanski, Carole SalaunMartin, and Hélène Sapin are employees of Eli Lilly; David Bruhn was an employee of Eli Lilly at the time of the study; and Jacek Kiljanski, Carole Salaun-Martin, and David Bruhn are holders of Eli Lilly shares and share options. Matthew Reaney and Hélène Sapin are not shareholders. Michael Theodorakis has declared that he has no conflicts of interest in this work.

\section{References}

1. Inzucchi SE, Bergenstal RM, Buse JB, et al; American Diabetes Association (ADA); European Association for the Study of Diabetes (EASD). Management of hyperglycemia in type 2 diabetes: a patient-centered approach: position statement of the American Diabetes Association (ADA) and the European Association for the Study of Diabetes (EASD). Diabetes Care. 2012;35(6):1364-1379.

2. Rodbard HW, Jellinger PS, Davidson JA, et al. Statement by an American Association of Clinical Endocrinologists/American College of Endocrinology consensus panel on type 2 diabetes mellitus: an algorithm for glycemic control. Endocr Pract. 2009;15(6):540-559.

3. Barnett AH, Burger J, Johns D, et al. Tolerability and efficacy of exenatide and titrated insulin glargine in adult patients with type 2 diabetes previously uncontrolled with metformin or a sulfonylurea: a multinational, randomized, open-label, two-period, crossover noninferiority trial. Clin Ther. 2007;29(11):2333-2348.

4. Heine RJ, Van Gaal LF, Johns D, et al. Exenatide versus insulin glargine in patients with suboptimally controlled type 2 diabetes: a randomized trial. Ann Intern Med. 2005;143(8):559-569.

5. Nauck MA, Duran S, Kim D, et al. A comparison of twice-daily exenatide and biphasic insulin aspart in patients with type 2 diabetes who were suboptimally controlled with sulfonylurea and metformin: a non-inferiority study. Diabetologia. 2007;50(2):259-267.

6. Davies MJ, Donnelly R, Barnett AH, Jones S, Nicolay C, Kilcoyne A. Exenatide compared with long-acting insulin to achieve glycaemic control with minimal weight gain in patients with type 2 diabetes: results of the Helping Evaluate Exenatide in patients with diabetes compared with Long-Acting insulin (HEELA) study. Diabetes Obes Metab. 2009;11:1153-1162.

7. Diamant M, Van Gaal L, Stranks S, et al. Once weekly exenatide compared with insulin glargine titrated to target in patients with type 2 diabetes (DURATION-3): an open-label randomised trial. Lancet. 2010;375(9733):2234-2243.

8. Russell-Jones D, Vaag A, Schmitz O, et al; Liraglutide Effect and Action in Diabetes 5 (LEAD-5) met+SU Study Group. Liraglutide vs insulin glargine and placebo in combination with metformin and sulfonylurea therapy in type 2 diabetes mellitus (LEAD-5 met+SU): a randomised controlled trial. Diabetologia. 2009;52(10):2046-2055.

9. National Institute for Health and Clinical Excellence (NICE). Type 2 diabetes: newer agents for blood glucose control in type 2 diabetes. NICE short clinical guideline 87. London: NICE; 2009 Available from: http://www.nice.org.uk/nicemedia/live/12165/44318/44318.pdf. Accessed January 23, 2013.

10. Bergenstal RM, Garrison LP Jr, Wintle M, et al. Exenatide bid observational study (ExOS): baseline population characteristics of a prospective research study to evaluate the clinical effectiveness of exenatide bid use in patients with type 2 diabetes in a real-world setting. Curr Med Res Opin. 2011;27(3):531-540.

11. Fabunmi R, Nielsen LL, Quimbo R, et al. Patient characteristics, drug adherence patterns, and hypoglycemia costs for patients with type 2 diabetes mellitus newly initiated on exenatide or insulin glargine. Curr Med Res Opin. 2009;25(3):777-786. 
12. Ryder RE, Thong KY, Cull ML, Mills AP, Walton C, Winocour PH. The Association of British Clinical Diabetologists (ABCD) nationwide exenatide audit. Pract Diab Int. 2010;27(8):352-357b.

13. Koro CE, Bowlin SJ, Bourgeois N, Fedder DO. Glycemic control from 1988 to 2000 among US adults diagnosed with type 2 diabetes: a preliminary report. Diabetes Care. 2004;27(1):17-20.

14. Tzoulaki I, Molokhia M, Curcin V, et al. Risk of cardiovascular disease and all cause mortality among patients with type 2 diabetes prescribed oral antidiabetes drugs: retrospective cohort study using UK general practice research database. BMJ. 2009;339:b4731.

15. Yurgin N, Secnik K, Lage MJ. Obesity and the use of insulin: a study of patients with type 2 diabetes in the UK. J Diabetes Complications. 2008;22(4):235-240.

16. Gedulin BR, Nikoulina SE, Smith PA, et al. Exenatide (exendin-4) improves insulin sensitivity and \{beta $\}$-cell mass in insulin-resistant obese fa/fa Zucker rats independent of glycemia and body weight. Endocrinology. 2005;146(4):2069-2076.

17. Nielsen LL, Young AA, Parkes DG. Pharmacology of exenatide (synthetic exendin-4): a potential therapeutic for improved glycemic control of type 2 diabetes. Regul Pept. 2004;117(2):77-88.

18. Garber AJ. Incretin effects on $\beta$-cell function, replication, and mass: the human perspective. Diabetes Care. 2011;34 Suppl 2: S258-S263.

19. Li Y, Hansotia T, Yusta B, Ris F, Halban PA, Drucker DJ. Glucagonlike peptide-1 receptor signaling modulates beta cell apoptosis. J Biol Chem. 2003;278(1):471-478.

20. Xu G, Stoffers DA, Habener JF, Bonner-Weir S. Exendin-4 stimulates both beta-cell replication and neogenesis, resulting in increased betacell mass and improved glucose tolerance in diabetic rats. Diabetes. 1999;48(12):2270-2276.

21. Liu SC, Tu YK, Chien MN, Chien KL. Effect of antidiabetic agents added to metformin on glycaemic control, hypoglycaemia and weight change in patients with type 2 diabetes: a network meta-analysis. Diabetes Obes Metab. 2012;14(9):810-820.

22. European Medicines Agency. Byetta: exenatide; assessment history [web page on the Internet]. London: European Medicines Agency; nd. Available from: http://www.ema.europa.eu/ema/ index.jsp?curl=pages/medicines/human/medicines/000698/human_ med_000682.jsp\&jsenabled=true. Accessed December 10, 2012.

23. Lilly. Byetta ${ }^{\circledR}$ approved for use with basal insulin in Europe [press release]. San Diego, CA: Amylin Pharmaceuticals; 2012 [March 23]. Available from: https://investor.lilly.com/releasedetail2. cfm?ReleaseID=659089. Accessed December 10, 2012.

24. Ligthelm RJ, Borzì V, Gumprecht J, Kawamori R, Wenying Y, Valensi P. Importance of observational studies in clinical practice. Clin Ther. 2007;29 Spec No:1284-1292.

25. Mann CJ. Observational research methods. Research design II: cohort, cross sectional, and case-control studies. Emerg Med J. 2003;20(1): 54-60.

26. Amylin Pharmaceuticals. CHOICE: CHanges to Treatment and Outcomes in Patients With Type 2 Diabetes Initiating InjeCtablE Therapy. In: ClinicalTrials.gov [website on the Internet]. Bethseda, MD: US National Library of Medicine; 2008 [updated April 12, 2010]. Available from: http://www.clinicaltrials.gov/ct2/show/NCT00635492. NLM identifier: NCT00635492. Accessed February 23, 2013.

27. Matthaei S, Reaney M, Mathieu C, et al. Patients with Type 2 Diabetes Initiating Exenatide Twice Daily or Insulin in Clinical Practice: CHOICE Study. Diabetes Ther. 2012;3(1):6.

28. Bergenstal RM, Garrison LP Jr, Miller LA, et al. Exenatide BID Observational Study (ExOS): results for primary and secondary endpoints of a prospective research study to evaluate the clinical effectiveness of exenatide BID use in patients with type 2 diabetes in a real-world setting. Curr Med Res Opin. 2011;27(12):2335-2342.

29. Jones S, Benroubi M, Castell C, et al. Characteristics of patients with type 2 diabetes mellitus initiating insulin therapy: baseline data from the INSTIGATE study. Curr Med Res Opin. 2009;25(3): 691-700.
30. Yue LQ. Statistical and regulatory issues with the application of propensity score analysis to nonrandomized medical device clinical studies. J Biopharm Stat. 2007;17(1):1-13.

31. Simpson A, Smith H, Nicolay C, et al. Approaches to initiation of insulin therapy in patients with type 2 diabetes and resulting outcomes at 12 months in four European countries: data from the INSTIGATE study. Poster presented at the World Congress on Controversies to Consensus in Diabetes, Obesity and Hypertension (CODHy), October 30-November 2, 2008, Barcelona, Spain.

32. Benroubi M, Schmitt H, Cleall SP, et al; the TREAT Study Investigators. Costs and clinical outcomes after 24 months of insulin therapy in patients with type 2 diabetes: results from the TREAT study. Poster presented at the 47th European Association for the Study of Diabetes (EASD) Annual Meeting, September 12-16, 2011, Lisbon, Portugal.

33. Blak BT, Smith HT, Hards M, Maguire A, Gimeno V. A retrospective database study of insulin initiation in patients with Type 2 diabetes in UK primary care. Diabet Med. 2012;29(8):e191-e198.

34. Gordon J, Pockett RD, Tetlow AP, McEwan P, Home PD. A comparison of intermediate and long-acting insulins in people with type 2 diabetes starting insulin: an observational database study. Int J Clin Pract. 2010; 64(12):1609-1618.

35. Hall GC, McMahon AD, Dain MP, Home PD. A comparison of duration of first prescribed insulin therapy in uncontrolled type 2 diabetes. Diabetes Res Clin Pract. 2011;94(3):442-448.

36. Buse JB, Henry RR, Han J, Kim DD, Fineman MS, Baron AD; Exenatide-113 Clinical Study Group. Effects of exenatide (exendin-4) on glycemic control over 30 weeks in sulfonylurea-treated patients with type 2 diabetes. Diabetes Care. 2004;27(11):2628-2635.

37. Kendall DM, Riddle MC, Rosenstock J, et al. Effects of exenatide (exendin-4) on glycemic control over 30 weeks in patients with type 2 diabetes treated with metformin and a sulfonylurea. Diabetes Care. 2005;28(5):1083-1091.

38. Buysschaert M, Preumont V, Oriot PR, et al; UCL Study Group for Exenatide. One-year metabolic outcomes in patients with type 2 diabetes treated with exenatide in routine practice. Diabetes Metab. 2010;36(5): 381-388.

39. Bunck MC, Diamant M, Cornér A, et al. One-year treatment with exenatide improves beta-cell function, compared with insulin glargine, in metformin-treated type 2 diabetic patients: a randomized, controlled trial. Diabetes Care. 2009;32(5):762-768.

40. DeFronzo RA, Ratner RE, Han J, Kim DD, Fineman MS, Baron AD. Effects of exenatide (exendin-4) on glycemic control and weight over 30 weeks in metformin-treated patients with type 2 diabetes. Diabetes Care. 2005;28(5):1092-1100.

41. Crasto W, Jarvis J, Khunti K, Davies MJ. New insulins and new insulin regimens: a review of their role in improving glycaemic control in patients with diabetes. Postgrad Med J. 2009;85(1003):257-267.

42. Vaag A, Lund SS. Insulin initiation in patients with type 2 diabetes mellitus: treatment guidelines, clinical evidence and patterns of use of basal vs premixed insulin analogues. Eur J Endocrinol. 2012;166(2):159-170.

43. Waugh N, Cummins E, Royle P, et al. Newer agents for blood glucose control in type 2 diabetes: systematic review and economic evaluation. Health Technol Assess. 2010;14(36):1-248.

44. Zinman B, Schmidt WE, Moses A, Lund N, Gough S. Achieving a clinically relevant composite outcome of an $\mathrm{HbA}_{1 \mathrm{c}}$ of $<7 \%$ without weight gain or hypoglycaemia in type 2 diabetes: a meta-analysis of the liraglutide clinical trial programme. Diabetes Obes Metab. 2012;14(1): $77-82$.

45. American Diabetes Association. Standards of medical care in diabetes-2012. Diabetes Care. 2012;35 Suppl 1:S11-S63.

46. Ryder RE, Thong K; ABCD nationwide exenatide and liraglutide audit contributors. ABCD nationwide exenatide and liraglutide audits. Presented at Diabetes UK Annual Professional Conference, March 30-April 1, 2011, London, UK 
Diabetes, Metabolic Syndrome and Obesity: Targets and Therapy

Dovepress

\section{Publish your work in this journal}

Diabetes, Metabolic Syndrome and Obesity: Targets and Therapy is opinion and commentaries are all considered for publication. The an international, peer-reviewed open-access journal committed to the rapid publication of the latest laboratory and clinical findings in the fields of diabetes, metabolic syndrome and obesity research. Original research, review, case reports, hypothesis formation, expert manuscript management system is completely online and includes a very quick and fair peer-review system, which is all easy to use. Visit $\mathrm{http}: / / \mathrm{www}$.dovepress.com/testimonials.php to read real quotes from published authors.

Submit your manuscript here: http://www.dovepress.com/diabetes-metabolic-syndrome-and-obesity-targets-and-therapy-journal 